Check for updates

The BMJ

Cite this as: $B M J 2020 ; 369: m 2421$ http://dx.doi.org/10.1136/bmj.m2421 Published: 17 June 2020

\section{Covid-19: Racism may be linked to ethnic minorities' raised death risk, says PHE}

\section{Gareth lacobucci}

Racism, discrimination, and social inequality may have contributed to the increased risk of death from covid-19 among ethnic minority groups, a review commissioned by the government has acknowledged.

The report from Public Health England, ${ }^{1}$ published on 16 June, follows a separate PHE report on 2 June that found that people from ethnic minorities were more likely to contract and die from covid-19 but that received heavy criticism for its lack of recommendations on how to reduce the disparities. ${ }^{2}$

The second report makes some recommendations (box 1), some of which were disclosed to The BMJ last week by disgruntled stakeholders who had expected them to be published with the first report. ${ }^{3}$

Box 1: PHE's key recommendations

- Make comprehensive ethnicity data collection and recording mandatory as part of routine NHS and social care data collection, including ethnicity data at death certification

- Support community research in which researchers and community stakeholders engage as equal partners to understand the social, cultural, structural, economic, religious, and commercial determinants of covid-19's effects in ethnic minorities

- Improve access, experiences, and outcomes of services for ethnic minorities through measures such as regular equality audits, health impact assessments, integration of equality into quality monitoring, and better representation at all staff levels

- Accelerate the development of culturally competent occupational risk assessment tools to reduce the risk of employees' exposure to and acquisition of covid-19, especially for key workers

- Fund, develop, and implement culturally competent covid-19 education and prevention campaigns in partnership with local ethnic minority and faith communities

- Accelerate efforts to target culturally competent health promotion and disease prevention programmes for non-communicable diseases

- Ensure that covid-19 recovery strategies actively reduce inequalities caused by the wider determinants of health to create sustainable change in the long term

Recommendations include enforcing the collection of ethnicity data at death certification to inform actions to mitigate the impact of covid-19 on ethnic minorities, supporting collaborative research to understand the wider determinants of covid-19 in these groups, and developing "culturally competent" occupational risk assessment tools to protect ethnic minority workers from covid-19.
The second report states clearly that factors such as racism, discrimination, and social inequality may have contributed to the increased risk of death from covid-19 among ethnic minority groups. Occupation is cited as another possible risk factor. It says that individuals and organisations who were consulted "pointed to racism and discrimination experienced by communities and more specifically by BAME [black, Asian, and minority ethnic] key workers as a root cause affecting health, and exposure risk and disease progression risk.”

It added, "Stakeholders expressed deep dismay, anger, loss, and fear in their communities about the emerging data and realities of BAME groups being harder hit by the covid-19 pandemic than others, exacerbating existing inequalities."

PHE said that the feedback it received indicated that "historical racism and poorer experiences of healthcare or at work may mean that individuals in BAME groups are less likely to seek care when needed or as NHS staff are less likely to speak up when they have concerns about personal protective equipment (PPE) or risk."

The report concluded: "The unequal impact of covid-19 on BAME communities may be explained by a number of factors ranging from social and economic inequalities, racism, discrimination and stigma, occupational risk, inequalities in the prevalence of conditions that increase the severity of disease including obesity, diabetes, CVD [cardiovascular disease] and asthma."

It said that further consideration needed to be given to factors such as diet, vitamin D levels, and housing.

Hina Shahid, a GP in London and chair of the Muslim Doctors Association, said that the report and its recommendations were welcome but that it "raised questions on the lack of transparency and mixed messages received surrounding its publication.”

She added, "Trust within the BAME community is at an all time low, and the government has significant work to do to rebuild this. We are pleased to see several of our recommendations included. The government needs to urgently engage with community organisations and leaders to implement the recommendations in ways that are robust and sustainable.”

Andrew Goddard, president of the Royal College of Physicians, said it remained unclear why this second report did not accompany the earlier PHE review. He said the recommendations "must be placed at the core of both the NHS and the government's plans to restart services, as well as plans for further covid-19 outbreaks." 
He added, "There is no time for complacency, and leaders at all levels should be made accountable for delivering these recommendations and regularly reporting on progress."

Goddard said that two weeks ago only $24 \%$ of college members said that they had undergone a formal risk assessment despite the NHS having known for weeks about the increased risk among ethnic minority staff, which he called "disappointing."

1 Public Health England. Beyond the data: understanding the impact of covid-19 on BAME groups. Jun 2020. https://assets.publishing.service.gov.uk/government/uploads/system/uploads/attachment_data/file/892376/COVID_stakeholder_engagement_synthesis_beyond_the_data.pdf.

2 Public Health England. Disparities in the risk and outcomes of covid-19. Jun 2020. https://assets.publishing.service.gov.uk/government/uploads/system/uploads/attachment_data/file/892085/disparities_review.pdf.

3 lacobucci G. Covid-19: PHE review has failed ethnic minorities, leaders tell BMJ. BMJ 2020;369:m2264. doi: 10.1136/bmj.m2264 pmid: 32513658

This article is made freely available for use in accordance with BMJ's website terms and conditions for the duration of the covid-19 pandemic or until otherwise determined by BMJ. You may use, download and print the article for any lawful, non-commercial purpose (including text and data mining) provided that all copyright notices and trade marks are retained. 